\title{
Facing racism and sexism in science by fighting against social implicit bias: a Latin and Black woman perspective.
}

\author{
Karin C. Calaza ${ }^{1,10,}{ }^{*}$, Fátima C. S. Erthal2,10, Mirtes G. Pereira ${ }^{3}$, Kita C. D. Macario ${ }^{4}$, \\ Verônica T. Daflon ${ }^{5}$, Isabel P. A. David ${ }^{3}$, Helena C. Castro ${ }^{6}$, Maria D. Vargas ${ }^{7}$, Laura B. \\ Martins $^{8}$, Jasmin B. Stariolo ${ }^{9}$, Eliane Volchan ${ }^{2,10,{ }^{*}}$ and Leticia de Oliveira ${ }^{3,10,11, *}$.
}

'Department of Neurobiology, Institute of Biology, Federal Fluminense University. Niterói. Rio de Janeiro. 24020-141. Brazil.

${ }^{2}$ Laboratory of Neurobiology. Institute of Biophysics Carlos Chagas Filho. Federal University of Rio de Janeiro. Rio de Janeiro. Rio de Janeiro. 21941-902. Brazil.

${ }^{3}$ Department of Physiology and Pharmacology, Biomedical Institute, Federal Fluminense University. Niterói. Rio de Janeiro. 24210-130. Brazil.

${ }^{4}$ Department of Physics. Institute of Physics. Federal Fluminense University. Niterói. Rio de Janeiro. 24210-346. Brazil.

${ }^{5}$ Department of Sociology and Methodology of Social Sciences. Institute of Human Sciences and Philosophy. Federal Fluminense University. Niterói. Rio de Janeiro. 24210-201. Brazil

${ }^{6}$ Department of Cellular and Molecular Biology. Institute of Biology. Federal Fluminense University. Niterói. Rio de Janeiro. 24020-141. Brazil.

${ }^{7}$ Chemistry Institute. Federal Fluminense University. Niterói. Rio de Janeiro. 24020-141. Brazil.

${ }^{8}$ Biomedical Institute. Federal Fluminense University. Niterói. Rio de Janeiro. 24210-130. Brazil.

${ }^{9}$ Institute of Biology. Federal Fluminense University. Niterói. Rio de Janeiro. 24210-130. Brazil.

${ }^{10}$ These authors contributed equally

${ }^{11}$ Lead Contact

*Correspondence: oliveira_leticia@id.uff.br, kcalaza@id.uff.br, evolchan@biof.ufrj.br 


\begin{abstract}
The editors of several major journals have recently asserted the importance of combating racism and sexism in science. This is especially relevant now, as the COVID-19 pandemic may have led to a widening of the gender and racial/ethnicity gaps. Implicit bias is a crucial component in this fight. Negative stereotypes that are socially constructed in a given culture are frequently associated with implicit bias (which is unconscious or not perceived). In the present article, we point to scientific evidence that shows the presence of implicit bias in the academic community, which contributes to strongly damaging unconscious evaluations and judgments of individuals or groups. Additionally, we suggest several actions aimed at (1) editors and reviewers of scientific journals, (2) people in positions of power within funding agencies and research institutions and (3) members of selection committees to mitigate this effect. These recommendations are based on the experience of a group of Latin American scientists comprising Black and Latin women, teachers and undergraduate students who participate in a women in science working group at universities in the state of Rio de Janeiro, Brazil. With this article, we hope to contribute to reflections, actions and the development of institutional policies that enable and consolidate diversity in science and reduce disparities based on gender and race/ethnicity.
\end{abstract}

Keywords: implict bias, gender disparity, diversity, racial dispariry

\title{
Introduction
}

"Science has a racism problem", claimed an editorial of the important journal "Cell" (Edge, 2020). Editors from a variety of respected scientific journals, such as Nature and Science, have recently asserted the importance of combating racism and sexism in science. Especially after the COVID-19 pandemic, several pieces of evidence suggest that gender and racial gaps may be widened (Collins et al., 2020; Myers et al., 2020; Staniscuaski et al., 2020a). For instance, Staniscuaski et al. (2020b), analyzing academic productivity, showed that male academics - especially childless academics - were the group least affected by the pandemic. 
In contrast, female academics, especially Black women and mothers, were the most impacted group.

Although the fight against racism and sexism in science involves several aspects, socially constructed implicit bias is a key component in this fight. "Bias" is a concept that refers to analysis, judgments, or attitudes that do not adhere to the principles of impartiality. Bias against a person or group can lead to unfair assessments. This judgmental bias can be explicit or implicit (not perceived), and it can occur due to skin color, ethnicity, religion, gender, sexual orientation, weight, physical or mental disability, among others (Greenwald and Krieger, 2006; Staats et al., 2015). Implicit (unconscious or unperceived) negative judgment bias in the academic sphere is generally associated with social stereotypes of individuals who are stigmatized as intellectually limited or incapable. Importantly, a social stereotype is a mental association of a social group or category with a characteristic or trait that may or may not be favorable (Greenwald and Krieger, 2006). In other words, stereotypes are socially constructed beliefs that do not necessarily reflect reality (Greenwald and Banaji, 1995; Allport, 1954; Ashmore and DelBoca, 1981). Such social constructions, which are determined by culture and the unequal distribution of resources and power in a community, have substantial influence on the unconscious evaluations and judgments of individuals or groups (Staats et al., 2015; Storage et al., 2016). Stereotypes that are repeatedly and imperceptibly transmitted through several information channels induce implicit beliefs that are used to organize and socially categorize the world and provide rationales for entrenched inequalities (Gaucher et al., 2011; Kang et al., 2012; Galvéz et al., 2019; Rivera and Tilcsik, 2019; Smith et al., 20191). These implicit associations are more prevalent than explicit prejudice, which means that even people who consciously believe in and defend the principles of justice and nondiscrimination can have their judgment affected by implicit bias, without their knowledge (Staats et al., 2014). In fact, evidence suggests that implicit bias can be a better predictor of behavior than explicit bias (Bargh \& Chartrand, 1999; Ziegert \& Hanges, 2005). While explicit biases are conscious attributions that are accessible through introspection, implicit biases are not consciously attainable. Nevertheless, implicit bias can be measured. Tony Greenwald (University of Washington), Mahzarin Banaji (Harvard University) and Brian Nosek (University of Virginia) created "Project Implicit" $=$ in 1998. They developed the Implicit Association Test (IAT) to reveal, for instance, the negative implicit associations between race and negative words. The IAT measures the power of the associations between stereotyped groups (e.g., Black people,

\footnotetext{
${ }^{1}$ Access: http://assets.uscannenberg.org/docs/aii-inequality-report-2019-09-03.pdf

${ }^{2}$ Access: https://www.projectimplicit.net/about.html
} 
gay people and women) and stereotyped domains (e.g., women and science versus men and science). The main idea is that respondents should show a faster response when related items share the same response key. There are many different types of IATs available, which allow for the examination of a variety of potential associations.

\section{Implicit gender bias}

Negative implicit stereotypes are shaped by experience and are based on implicit learned associations between the culturally construed putative characteristics of members of social categorical groups, including those based on race, gender, and socioeconomic status. The presence of these stereotypes leads to implicit bias in judgments of stigmatized individuals or groups (Greenwald and Banaji, 1995). The formation of implicit gender stereotypes, which associate characteristics of exceptional brilliance and intelligence to the male gender, seems to start early in life (Bian et al., 2017) and is reinforced by daily experiences in which members of a categorical group appear to be associated with economic precariousness and a lack of power (Tilly, 1998). In a study by Bian and collaborators (2017), children from 5 to 7 years old listened to a text that described a brilliant person. Then, children viewed pictures of women's and men's faces and were asked to indicate which person was the character in the story. Among the five-year-old children, both boys and girls chose photos of people of their own gender. However, among children aged 6 and older, only boys continued to indicate the pictures of people of their own gender as the brilliant character in the story, while girls became less likely to choose photos of women. Considering that children at this age generally show positive biases towards their own in-groups (e.g., those of the same gender), this result suggests that the consequences of the stereotype that brilliance is a male characteristic occur very early and that this stereotype already begins to impact girls between 5 and 6 years old (Bian et al., 2017). Interestingly, a study showed that national gender differences in science and math success are associated with national differences in implicit gender-science stereotypes. Specifically, the stronger the nation's citizens' implicit association of men with science and women with the liberal arts, the greater the gap between female and male adolescents' eighth-grade science achievement in that nation (Nosek et al. 2009). There is evidence that implicit bias acts incisively in adulthood, harming women. One study showed that when university faculty (both men and women) analyzed an identical curriculum for a lab manager position with either a male or a female name, the faculties evaluated the curriculum with a male name as more competent and deserving a higher salary (Moss-Racusin et al., 2012). In 
the same vein, Reuben et al. (2014) carried out a study in which participants (men and women) who were volunteers in laboratory research were rewarded for "hiring" a good candidate to perform mathematical tests. Women were systematically less chosen than men in all three experimental conditions tested: (a) a condition in which no skill information and only information about the physical appearance of the candidates was provided, (b) a condition in which the candidates could give a speech to talk about their mathematical skills, and (c) a condition in which information about the candidates' performance on a previous math test was provided. Interestingly, in this last experimental condition, the power of the effect of implicit bias was clearly demonstrated, as the "employers" preferred to choose men with low performance in mathematics over women with good performance. The authors also reported that in condition (b), when the candidates were allowed to talk about their skills, the male candidates overestimated their math skills, while the female candidates did the opposite.

The presence of this implicit bias against women causes considerable damage to the development of their scientific careers. Only $18.1 \%$ of articles published in high-impact journals (Nature research journals) have women as senior authors (last authorship), and the higher the journal's impact index is, the smaller the number of women listed as the principal author (Bendels et al., 2018). In addition, articles with women as the principal author are less cited than those with men as the principal author (Larivière et al., 2013). Recently, Dworkin et al. (2020) analyzed high-impact neuroscience journals and found that papers with men listed as the first or last author were cited $11.6 \%$ more than expected given the proportion of such articles in the field, and papers with women listed as the first or last authors were cited $30.2 \%$ less than expected. Importantly, however, when articles are reviewed anonymously (doubleblind review), the number of articles published with women listed as the first author increases (Budden et al., 2008), highlighting the impact of implicit bias in this process. Women who have authored the same number of publications with the same publication impact as men are less likely to become research leaders (Van Dijk et al., 2014). Additionally, letters of recommendation written for women use significantly fewer adjectives that represent intelligence and brilliance (Dutt et al., 2016; Kuo, 2016³).

In terms of research funding, the effects of implicit bias against women are also significant. A study based on data from a Swedish funding agency reported that women need to author twice as many publications to obtain the same scientific competence score as men (Wold and Wenneras, 1997). Recently, a study based on funding provided by the NIH (a US research funding agency and one of the largest such agencies in the world) revealed that men obtain

\footnotetext{
${ }^{3}$ Access: https://www.sciencemag.org/careers/2016/10/recommendation-letters-reflect-gender-bias
} 
more funding renewal than women (Pohlhaus et al., 2011). A Dutch study showed no difference between men and women in the quality of the research proposal/project submitted for funding. However, in their sample, women received less funding due to lower scores in the "quality of the researcher" (Van der Lee and Ellemers, 2015). In the same vein, a Canadian study showed that the funding gap is generated by an unfavorable view of women as scientific leaders and not based on the quality of their studies (Witteman et al., 2019). Importantly, when evaluation committees of funding agencies are aware of gender bias against women, the unequal distribution of funding between men and women is less likely to occur (Régner et al., 2019).

\section{Implicit racial/ethnicity bias}

Although the studies discussed above focus on gender stereotypes, the literature also describes implicit judgment bias based on skin color and ethnicity. For example, in one study, fictitious resumes with white-sounding names received $50 \%$ more callbacks for interviews than resumes with African-American-sounding names (Bertrand and Mullainathan, 2004). Jaxon et al. (2019) demonstrated in children that the association of brilliance with male gender might depend on the race of the person being evaluated. This intersectional study showed that children associated brilliance with white men but not with Black men (Jaxon et al., 2019). Storage et al. (2016) evaluated the frequency with which college students commented whether their professors were "brilliant" or a "genius" in course reviews on a popular website (RateMyProfessor.com). They showed that fields in which "brilliant" and "genius" appeared more often were also less likely to be pursued by African-American PhDs, predicting diversity at the PhD level. This evidence indicates a strong racial bias that helps explain, for instance, the extremely low percentage of faculty positions and PhDs earned by African Americans in STEM (National Science Foundation, 2015; U.S. Department of Education, 2017; Bernard and Cooperdock, 2018). Baron et al. (2006) used an adaptation of the IAT to measure racial bias in children and showed that negative implicit race bias develops early in the lives of white children. The authors also observed that explicit beliefs about race became more egalitarian over time, but implicit race bias remained unchanged.

In a very recent interesting study, Eaton and collaborators (2020) probed the implicit bias for gender and its association with race/ethnicity. The authors developed an experimental design in which physics professors from US research universities were asked to evaluate identical curriculum vitae (CV) depicting a hypothetical doctoral graduate applying for a postdoctoral position in their field. The reviewers were asked to rate the candidate on 
competence, hireability, and likeability. The candidate's name on the CV was used to manipulate race/ethnicity (Asian, Black, Latinx, and white) and gender (female or male), with all other aspects of the $\mathrm{CV}$ being the same across conditions. The authors found an interaction between candidate gender and race/ethnicity. Black women and Latin candidates were rated the lowest in hireability. This result suggested the robust combined effect of gender and racial/ethnicity biases.

The stereotype of being incompetent/unreliable (Fiske, 1999; Jimeno-Ingrum et al., 2009; Pérez, 2010) creates unfair disadvantages for Latin scientists, especially in the context of leadership roles or to gain recognition for their studies. The persistent lack of Latin and African representation on editorial boards is an example of the consequences of racism in the academic world (Espin et al., 2017). Latin exclusion is so problematic that even the most applied test used to detect/study automatic attitudes and implicit bias, IAT, does not include this topic. The first study to establish an IAT for Latin was developed more than 10 years later than IAT (Pérez et al., 2010). Thus, discussions about implicit bias and stereotypes and their harmful effects are imperative in science and should consider the intersections between gender and race/ethnicity.

\section{Stereotype threat}

Another harmful consequence of unfounded cultural stigma is low performance on cognitive tasks generated by the threat of stereotypes. Stereotype threat is a psychological phenomenon that involves people feeling at risk of conforming to negative stereotypes about their social group (Steele and Aronson, 1995; see also the review by Spencer et al, 2016), and it has been suggested to be a key component of long-standing racial and gender gaps in academic performance (Osborne, 2001; Gilovich et al., 2006). Stereotype threat makes an individual feel a sense of exclusion and lack of belonging that generates psychological stress or anxiety and impairs performance in different situations. This sense of exclusion is especially harmful to humans since we are considered ultrasocial and depend on each other for basic survival (Tomasello, 2014). Human beings have a constant motivation to form and maintain lasting, positive, and significant interpersonal relationships, even in only a minimal number of these relationships (Baumeister and Leary, 1995). Social exclusion is alarming, distressing, and painful. Studies have indicated that the pain of social exclusion shares the neural substrates of physical pain (Kross et al., 2011; Eisenberger, 2012). 
Stereotype threat also reduces working memory capacity (Schmader and Johns, 2003; Rydell et al., 2009), which is extremely important to perform well in tasks. Working memory is diverted to address the survival-related threat of social exclusion through intrusive thoughts, anxiety, and stress that are imposed by stereotype threat (Schmader and Johns, 2003). Thus, unsurprisingly, the stress due to stereotype threat leads to a reduction in performance. Studies in this area have shown that participants who perform a task designed to activate stereotypes perform worse on the task (Pennington et al., 2016). In the seminal studies by Claude Steele and Joshua Aronson, the authors showed that African-American students performed worse than European-American college students on a verbal task under an experimental condition of stereotype threat, in which the task was described as a "diagnostic of intellectual ability". In the nonstereotype threat condition, in which the task was described as "a laboratory problemsolving task that was nondiagnostic of ability", Black and white participants performed equally (Steele and Aronson, 1995). Further, Johns et al. (2005) performed a study in which men and women completed difficult math problems that were described as a problem-solving task "for a study of general aspects of cognitive processes" or a math test "for a study of gender differences in mathematics performance". As expected, the results showed that women performed worse than men when the problems were described as a math test because of the stereotype threat created by the association between women and poor performance in math. Interestingly, when the participants were informed about the stereotype threat phenomenon, the differences in performance between women and men disappeared, indicating that "knowing is half the battle", as the authors suggested in the paper title. Considering these data, individual and institutional actions to disseminate this knowledge about stereotype threat are fundamental to reducing it among stereotyped groups. We believe these actions would be a powerful approach to fight racism, gender disparity and the false belief of low intellectual ability of those from disadvantaged socioeconomic environments.

In sum, there is ample evidence indicating the presence of unseen forces that work to prevent the progression of women, Latin, and Black people to positions of greater prominence and leadership, including in the academic world. In figures 1, 2 and 3, we suggest several actions aimed at (1) editors and reviewers of scientific journals, (2) people in positions of power within funding agencies and research institutions (3) to members of selection committees to mitigate this effect. These recommendations are based on the experience of a group of Latin American scientists comprising Black and Latin women, teachers and undergraduate students who participate in a women in science working group at universities in the state of Rio de Janeiro, Brazil. 


\section{RECOMMENDATIONS TO EDITORS AND REVIEWERS OF SCIENTIFIC JOURNALS}

1 Observe the number of publications submitted by negatively stereotyped groups, and ensure that this information is being collected and analyzed in your scientific journal.

2 Be aware that implicit bias is present in all of us and works actively against negatively stereotyped groups.

3 Make reviews double-blind whenever possible.

4 Establish a minimum of publications submitted by negatively stereotyped groups and fulfill this goal.

5 If there is any potential in the paper submitted by a negatively stereotyped group, give these groups a chance. Send the group a clear analysis of the weaknesses of the study and assume the revision will be strong.

6 Whenever possible, give more detailed feedback on the exact reasons for the refusal. This approach has a great educational effect and generates a feeling of inclusion. Paying attention to these groups increases self-esteem and can have transformative effects.

1 Negatively stereotyped groups find it difficult to choose the journals with the best scope for their study; help with this whenever possible.

8 Be aware that requiring the same performance for groups from quite different starting points is not fair. If opportunities are not generated, the exclusion cycle will never be broken. Obviously, the standard quality criteria must be respected.

9 Always try to empathize and imagine what the difficulties are for someone who is in a negatively stereotyped group. Writing and discussing in a nonnative language, for example, are extremely challenging.

Figure 1. Suggestions to people in positions of power within scientific journals. 


\section{RECOMMENDATIONS TO PEOPLE IN POSITIONS OF POWER WITHIN FUNDING AGENCIES AND RESEARCH INSTITUTIONS}

1 When referring someone to an important position, expand your list and think of someone from a negatively stereotyped group who could occupy that position of power. Think twice. Arguing that these people do not exist is not a valid argument in most cases.

2 Try to respect and value different views of the world and the experiences of people from negatively stereotyped groups. The advantage of diversity is having people on the team who think differently.

3 If you are in positions of power within funding agencies, universities and research institutions, you must create diversity committees to develop local policies to improve the participation of Black and Latin people, women and other minorities in science.

4 Maternity support policies should be implemented.

5 Diversity policies should also be developed for the top positions at these institutions.

6 Funding agencies should ask applicants to indicate in their proposals what actions are being taken in their research groups to increase diversity by decreasing the gender gap and racism in science.

Figure 2. Suggestions to people in positions of power within funding agencies and research institutions. 


\section{RECOMMENDATIONS TO MEMBERS OF SELECTION COMMITTEES}

1 The evaluation committee must be balanced in its race, ethnicity and gender composition.

2 The members of a selection committee should use the Implicit Association Test (https:/limplicit.harvard.edu/implicit/) to recognize their own implicit bias and consciously attempt to control it. Educational programs should be carried out to assess these biases in members of the evaluation committee and to teach strategies on how to minimize them.

3 Evaluations should be performed based on objective criteria that are previously established instead of using "intuition".

4 Members of the committee should make their own ranking lists before listening to the other members.

5 Whenever possible, the committee should make the selection (or complete stages of the selection process) without knowing the candidates' identities. Interview questions should be similar across candidates.

6 For interviews, committee members should ask questions related to professional issues. Personal questions, such as family planning, should not be asked.

1 All committee members should be heard, and the committee should take time for reflection to consider everyone's opinion.

8 Committee members should avoid making jokes or comments that call attention to gender or racial/ethnicity bias ("Nowadays, everything is considered prejudice") with other committee members and especially with candidates.

Figure 3. Suggestions to people in positions of power within selection committees.

Conclusions

Converging evidence in the literature suggests that explicit and implicit biases related to gender and race/ethnicity are powerful forces that foster the disparities and inequalities found in our society. Cognitive control can allow individuals to more easily refute explicit bias as they consciously perceive it. However, implicit bias is more prevalent than explicit bias. Therefore, it is crucial to increase awareness of the commonly ignored implicit biases so that each of us can cognitively resignify them. Additionally, institutions must submit proposals to mitigate this problem. With this article, we hope to contribute to reflections, actions, and the development of institutional policies that enable and consolidate diversity in science and reduce disparities in gender, race/ethnicity, which is essential to improve innovation and, therefore, the progress of inclusive science. If we want to combat racism and sexism in science, we need to combat socially constructed implicit bias. This issue is especially important now, as the COVID-19 pandemic may widen the gender and racial gap. Implicit bias is an unseen force that prevents us from moving towards the construction of a more inclusive and diverse science. 


\section{REFERENCES}

Allport, G. W. (1954). The nature of prejudice. Cambridge, MA: Addison-Wesley.

Anteneodo, C., Brito C., Alves-Brito, A., Alexandre, S. S., D’Avila, B. N. and Menezes, D. P. (2020). Brazilian physicists community diversity, equity, and inclusion: A first diagnostic. Physical Review. Physics Education Research. 16(1), 010136.

Ashmore, R. D., and Del Boca, F. K. (1981). Conceptual approaches to stereotypes and stereotyping. Cognitive processes in stereotyping and intergroup behavior. Hamilton D. L. (Ed.), Hillsdale, NJ: Erlbaum, 1-36.

Bargh, J. A., and Chartrand, T. L. (1999). The unbearable automaticity of being. American Psychologist. 54(7), 462-479.

Baron, A. S., and Banaji, M. R. (2006). The development of implicit attitudes: Evidence of race evaluations from ages 6 and 10 and adulthood. Psychological Science. 17(1), 53-58.

Baumeister, R. F., and Leary, M. R. (1995). The need to belong: desire for interpersonal attachments as a fundamental human motivation. Psychological Bulletin. 117(3), 497.

Bendels, M. H., Müller, R., Brueggmann, D., and Groneberg, D. A. (2018). Gender disparities in high-quality research revealed by Nature Index journals. PloS one. 13(1), e0189136.

Bernard, R. E., and Cooperdock, E. H. (2018). No progress on diversity in 40 years. Nature Geoscience. 11(5), 292-295.

Bertrand, M., and Mullainathan, S. (2004). Are Emily and Greg more employable than Lakisha and Jamal? A field experiment on labor market discrimination. American Economic Review. 94(4), 991-1013. 
Bian, L., Leslie, S. J., and Cimpian, A. (2017). Gender stereotypes about intellectual ability emerge early and influence children's interests. Science. 355(6323), 389-391.

Budden, A. E., Tregenza, T., Aarssen, L. W., Koricheva, J., Leimu, R., and Lortie, C. J. (2008). Double-blind review favours increased representation of female authors. Trends in Ecology \& Evolution. 23(1), 4-6.

Collins, C., Landivar, L. C., Ruppanner, L., and Scarborough, W. J. (2020). COVID-19 and the gender gap in work hours. Gender, Work \& Organization. 1-12.

Darley, J. M., and Gross, P. H. (1983). A hypothesis-confirming bias in labeling effects. Journal of Personality and Social Psychology. 44(1), 20-33.

Dworkin, J. D., Linn, K. A., Teich, E. G., Zurn, P., Shinohara, R. T., and Bassett, D. S. (2020). The extent and drivers of gender imbalance in neuroscience reference lists. Nature Neuroscience. 23, 918-926.

Dutt, K., Pfaff, D. L., Bernstein, A. F., Dillard, J. S., and Block, C. J. (2016) Gender differences in recommendation letters for postdoctoral fellowships in geoscience. Nature Geoscience. 9 (11), 805-808.

Eaton, A. A., Saunders, J. F., Jacobson, R. K., and West, K. (2020). How gender and race stereotypes impact the advancement of scholars in STEM: Professors' biased evaluations of physics and biology post-doctoral candidates. Sex Roles. 82(3-4), 127-141.

Edge, L. (2020). Science Has a Racism Problem. Cell 181, 1443-1444.

Eisenberger, N. I. (2012). The neural bases of social pain: evidence for shared representations with physical pain. Psychosomatic Medicine. 74(2), 126. 
Espin, J., Palmas, S., Carrasco-Rueda, F., Riemer, K., Allen, P. E., Berkebile, N., ... \& Rios, C. (2017). A persistent lack of international representation on editorial boards in environmental biology. PLoS biology, 15(12), e2002760. https://doi.org/10.1371/journal.pbio.2002760

Fiske, S. T., Xu, J., Cuddy, A. C., \& Glick, P. (1999). (Dis) respecting versus (dis) liking: Status and interdependence predict ambivalent stereotypes of competence and warmth. Journal of social issues, 55(3), 473-489.

Gálvez, R.H., Tiffenberg, V. \& Altszyler, E. (2019). Half a Century of Stereotyping Associations Between Gender and Intellectual Ability in Films. Sex Roles 81, 643-654.

https://doi.org/10.1007/s11199-019-01019-x

Gaucher, D., Friesen, J. and Kay, A. C. (2011). Evidence that Gendered Wording in Job Advertisements exist and sustains gender inequality. Journal of Personality and Social Psychology. Advance online publication.

Gilovich, T., Keltner, D., and Nisbett, R. E. (2006). Being a member of a stigmatized group: stereotype threat.Social Psychology. New York: WW Norton, 467-468.

Greenwald, A. G., and Banaji, M. R. (1995). Implicit social cognition: attitudes, self-esteem, and stereotypes. Psychological Review. 102(1), 4-27.

Greenwald, A. G., and Krieger, L. H. (2006). Implicit bias: Scientific foundations. California Law Review. 94(4), 945-967.

Harris, M., Macinko, J., Jimenez, G., \& Mullachery, P. (2017). Measuring the bias against lowincome country research: an Implicit Association Test. Globalization and health, 13(1), 80. DOI 10.1186/s12992-017-0304-y 
Jaxon, J., Lei, R. F., Shachnai, R., Chestnut, E. K., and Cimpian, A. (2019). The acquisition of gender stereotypes about intellectual ability: Intersections with race. Journal of Social Issues. 75(4), 1192-1215.

Jimeno-Ingrum, D., Berdahl, J. L., \& Lucero-Wagoner, B. (2009). Stereotypes of Latinos and Whites: Do they guide evaluations in diverse work groups?. Cultural Diversity and Ethnic Minority Psychology, 15(2), 158. DOI: 10.1037/a0015508.

Johns, M., Schmader, T., and Martens, A. (2005). Knowing is half the battle: Teaching stereotype threat as a means of improving women's math performance. Psychological Science. 16(3), 175-179.

Kang, J. (2012). Communications law: bits of bias. In: Implicit racial bias across the law I., J. D. Levinson and R. J. Smith. ed (Cambridge, England: Cambridge University Press), pp. 132-145.

Kross, E., Berman, M. G., Mischel, W., Smith, E. E., and Wager, T. D. (2011). Social rejection shares somatosensory representations with physical pain. PNAS. 108(15), 6270-6275.

Larivière, V., Ni, C., Gingras, Y., Cronin, B., and Sugimoto, C. R. (2013). Bibliometrics: Global gender disparities in science. Nature News. 504(7479), 211.

Moss-Racusin, C. A., Dovidio, J. F., Brescoll, V. L., Graham, M. J., and Handelsman, J. (2012). Science faculty's subtle gender biases favor male students. Proceedings of the National Academy of Sciences. 109(41), 16474-16479.

Myers, K. R., Tham, W. Y., Yin, Y., Cohodes, N., Thursby, J. G., Thursby, M. C., Schiffer, P., Walsh, J. T., Lakhani, K. R., and Wang, D. (2020). Unequal effects of the COVID-19 pandemic on scientists. Nature Human Behaviour. 1-4. 
National Science Foundation, National Center for Science and Engineering Statistics. (2015).

Science and engineering degrees, by race/ethnicity of recipients: 2002-12. Arlington, VA:

Author.

Nosek, B. A. et al. (2009). National differences in gender-science stereotypes predict national sex differences in science and math achievement. PNAS. 106(26), 10593-10597.

Osborne, J. W. (2001). Testing stereotype threat: Does anxiety explain race and sex differences in achievement?. Contemporary Educational Psychology. 26(3), 291-310.

Pennington, C. R., Heim, D., Levy, A. R., and Larkin, D. T. (2016). Twenty years of stereotype threat research: A review of psychological mediators. PloS one. 11(1), e0146487.

Pérez, E. O. (2010). Explicit evidence on the import of implicit attitudes: The IAT and immigration policy judgments. Political Behavior, 32(4), 517-545. DOI 10.1007/s11109-0109115-z.

Pohlhaus, J. R., Jiang, H., Wagner, R. M., Schaffer, W. T., and Pinn, V. W. (2011). Sex differences in application, success, and funding rates for NIH extramural programs. Academic Medicine. 86(6), 759-767.

Régner, I., Thinus-Blanc, C., Netter, A., Schmader, T., and Huguet, P. (2019). Committees with implicit biases promote fewer women when they do not believe gender bias exists. Nature Human Behavior. 3, 1171-1179.

Reuben, E. Sapienza, P., and Zingales, L. (2014). How stereotypes impair women's careers in science. PNAS. 111(12), 4403-4408.

Rivera, L. A. and Tilcsik, A. (2019). Scaling Down Inequality: Rating Scales, Gender Bias, and the Architecture of Evaluation. American Sociological Review. 84(2), 248-274. 
Rydell, R. J., McConnell, A. R., and Beilock, S. L. (2009). Multiple social identities and stereotype threat: imbalance, accessibility, and working memory. Journal of Personality and Social Psychology. 96(5), 949-966.

Schmader, T., and Johns, M. (2003). Converging evidence that stereotype threat reduces working memory capacity. Journal of Personality and Social Psychology. 85(3), 440-452.

Spencer, S. J., Logel, C., \& Davies, P. G. (2016). Stereotype threat. Annual review of psychology, 67, 415-437. DOI: 10.1146/annurev-psych-073115-103235.

Staats, C., Capatosto, K., Wright, R. A., and Contractor, D. (2015). State of the science: Implicit bias review 2015 (Vol. 3). Columbus, OH: Kirwan Institute for the Study of Race and Ethnicity.

Staats, C., Capatosto, K., Wright, R., and Jackson, V. (2014). 2014 State of the Science: Implicit Bias Review. Kirwan Institute for the Study of Race and Ethnicity.

Staniscuaski, F., Neumann, A., Schwartz, D., Vanessa, I., Kikuchi, T., Sayuri, A., Seixas, A., Kmetzsch, L., Reichert, F., Werneck, P. F., Oliveira, L., Mello-carpes, B. P., Soletti, R., Infanger, A. C., Zandona, E., and Klein, R. (2020a). Impact of COVID-19 on academic mothers. Science. Volume 368, Pags. 724.1-724.

Staniscuaski, F., Kmetzsch, L., Zandona, E., Reichert, F., Soletti, R. C., Ludwig, Z. M., Lima, E. F., Neumann, A., Schawartz, I.D, Mello-Carpes, P.B., Tamajusuku, A. S., Werneck, F. P., Ricachenevsky, F. K., Infanger, C., Seixas, A., Staats, C. C. \& Oliveira, L. (2020b). Gender, race and parenthood impact academic productivity during the COVID-19 pandemic: from survey to action. bioRxiv. 2020.07.04.187583; doi: https://doi.org/10.1101/2020.07.04.187583

Steele, C. M., and Aronson, J. (1995). Stereotype threat and the intellectual test performance of African Americans. Journal of Personality and Social Psychology. 69(5), 797-811. 
Storage, D., Horne, Z., Cimpian, A., and Leslie, S. J. (2016). The frequency of "brilliant" and "genius" in teaching evaluations predicts the representation of women and African Americans across fields. PloS one. 11(3), e0150194.

Tilly, Charles. (1998). Durable Inequality. Berkeley, CA: University of California Press.

Tomasello, M. (2014). The ultra-social animal. European Journal of Social Psychology. 44(3), 187-194.

U.S. Department of Education. (2017). Table 318.45. Number and percentage distribution of science, technology, engineering, and mathematics (STEM) degrees/certificates conferred by postsecondary institutions, by race/ethnicity, level of degree/certificate, and sex of student: 2008-09 through 2015-16. Retrieved April 25, 2019 from https://nces.ed.gov/programs/digest/d17/tables/dt17 318.45.asp.

Van der Lee, R., and Ellemers, N. (2015). Gender contributes to personal research funding success in The Netherlands. Proceedings of the National Academy of Sciences. 112(40), 1234912353.

Van Dijk, D., Manor, O., and Carey, L. B. (2014). Publication metrics and success on the academic job market. Current Biology. 24(11), 516-517.

Witteman, H. O., Hendricks, M., Straus, S. and Tannenbaum, C. (2019). Are gender gaps due to evaluations of the applicant or the science? A natural experiment at a national funding agency. The Lancet. 393(10171), 531-540.

Wold, A., and Wenneras, C. (1997). Nepotism and sexism in peer review. Nature. 387(6631), 341-343. 
Ziegert, J. C., and Hanges, P. J. (2005). Employment Discrimination: The Role of Implicit Attitudes, Motivation, and a Climate for Racial Bias. Journal of Applied Psychology. 90 (3), 553562. 